\title{
TOXICIDADE DO EFLUENTE DERIVADO DO TERMINAL MARÍTIMO DA PETROBRÁS SOBRE O GASTROPODA Costoanachis sertulariarum
}

\author{
Eduinetty Ceci Pereira Moreira de Sousa \& Luiz Roberto Tommasi \\ Instituto Oceanográfico da Universidade de São Paulo \\ (Caixa Postal 66149, 05315-970 São Paulo, SP, Brasil)
}

- Descriptors: Marine toxicology, Bioassays, Gastropod, Costoanachis sertulariarum, Petroleum.

- Descritores: Toxicologia marinha, Testes de toxicidade, Gastropoda, Costoanachis sertulariarum, Petróleo.

É importante o conhecimento dos efeitos toxicológicos de efluentes industriais antes de sua disposição oceânica através de emissários submarinos, para que se possa tratá-los adequadamente de modo a que não induzam impactos ecológicos no corpo hídrico costeiro receptor. Face à isso, neste trabalho são apresentados os resultados da avaliação da toxicidade de amostras de um efluente simulado, semelhante ao que a PETROBRÁs (Petróleo Brasileiro S/A) pretende vir a lançar no Canal de São Sebastião, SP. Esse efluente é composto de água residual fóssil extraída juntamente com o petróleo, de águas marinhas contaminadas por resíduos oleosos, bem como, por substâncias segregadas da água de lastro de embarcações e outros produtos.

Foram ensaiadas duas simulações do efluente (amostras A e B), previamente tratadas para redução dos compostos fenólicos e sulfetos, de acordo com a metodologia aplicada rotineiramente por aquela empresa. Como as amostras utilizadas eram hipersalinas (Tab. 1), elas foram ajustadas e acondicionadas conforme descrito por Phan et al. ( 1994 ).

Foram medidos: $\mathrm{pH}$, salinidade, Demanda Biológica de Oxigênio (DBO), Demanda Química de Oxigênio (DQO), óleos e graxas (OG), sulfetos, fenóis e concentração de amônia (APHA, 1985), no início e após um determinado tempo de estocagem (Tab. 1). Os resultados dessas análises mostraram existir diferenças significativas nas composições das amostras.

Os dados de $\mathrm{pH}$, concentração de oxigênio dissolvido e concentração de amônia das duas amostras, e nas diversas concentrações utilizadas, no início e final dos experimentos, encontram-se nas Tabelas 2 (amostra A) e 3 (amostra B).

Nos ensaios foram utilizados gastrópodes adultos, de aproximadamente $3 \mathrm{~mm}$ de comprimento, da espécie Costoanachis sertulariarum Orbigny, 1939 (Columbellidae). Estes organismos foram escolhidos por possuírem opérculo vestigial, o que permite seu contato permanente com o meio. Os espécimens foram aclimatados em aquários, contendo água do mar filtrada, aerada, com salinidade 36 , temperatura constante $\left(24 \pm 1^{\circ} \mathrm{C}\right)$ e períodos de 12 horas luz/12 horas escuro, durante 7 dias. Nesse período os animais foram alimentados com fragmentos de filé de peixe $e$ de camarão.

Foram realizados experimentos prévios, com o objetivo de determinar a faixa de diluições das amostras A e B, a serem empregadas nos testes subsequientes. Os resultados indicaram concentrações de 1 a $50 \%$ para a amostra $A$ e de 0,005 a $0,800 \%$ para a B. Foram também feitas observações sobre 0 comportamento dos animais durante os testes.

Os testes foram estáticos, com duração de 96 horas, realizados em incubadoras com temperatura de $24 \pm 1^{\circ} \mathrm{C}$, salinidades 36 (amostra A) e 38 (amostra B) e simulação de períodos diurno e noturno. Durante os testes os animais não foram alimentados. A contagem dos organismos foi realizada a cada 24 horas, sendo os indivíduos mortos retirados. O experimento consistiu na exposição dos animais às diferentes concentrações das amostras A e B. Nos experimentos foram utilizados bequeres de $400 \mathrm{ml}$ de capacidade, contendo $250 \mathrm{ml}$ de solução teste, sem aeração e foram colocados 10 animais na amostra $\mathrm{A}$ 15 na amostra B. Todas as concentrações tiveram 5 réplicas (Fig. 1). 
Tabela 1. Dados de salinidade, pH, DBO, DQO, OG, sulfetos, fenóis e amônia, das amostras A e B no início $(0 \mathrm{~h})$ e após um determinado período de estocagem

\begin{tabular}{cccccccccc}
\hline Amostra & $\begin{array}{c}\text { Tempo } \\
(\mathrm{h})\end{array}$ & Salinidade & $\mathbf{p H}$ & $\begin{array}{c}\text { DBO } \\
\left(\mathrm{mg} / \mathrm{O}_{2}\right)\end{array}$ & $\begin{array}{c}\text { DQO } \\
\left(\mathrm{mg} / \mathrm{IO}_{2}\right)\end{array}$ & $\begin{array}{c}\text { OG } \\
(\mathrm{mg} / \mathrm{l})\end{array}$ & $\begin{array}{c}\text { Sulfetos } \\
(\mathrm{mg} / \mathrm{l})\end{array}$ & $\begin{array}{c}\text { Fenóis } \\
(\mathrm{mg} / \mathrm{l})\end{array}$ & $\begin{array}{c}\text { Amônia } \\
(\mu \mathrm{M} / \mathrm{L})\end{array}$ \\
\hline $\mathbf{A}$ & 0 & 67 & 6,78 & 62 & 84 & 6 & - & 0,36 & 700 \\
& 204 & 67 & - & 650 & 2218 & 18 & - & - & - \\
B & 0 & 62 & 6,44 & 423 & 889 & 30 & 11 & 1,32 & 59,24 \\
& 240 & 62 & - & 50 & 195 & 4 & 2,8 & 1,14 & - \\
\hline
\end{tabular}

Phan et al., 1994

Tabela 2. Dados de $\mathrm{pH}$, concentrações de oxigênio e de amônia, no início $(0 \mathrm{~h})$ e no final $(96 \mathrm{~h})$ do experimento, nas várias concentrações utilizadas da amostra $\mathrm{A}$

\begin{tabular}{|c|c|c|c|c|c|c|}
\hline \multirow[t]{2}{*}{$\begin{array}{c}\text { Concentração } \\
(\%)\end{array}$} & \multicolumn{2}{|c|}{ pH } & \multicolumn{2}{|c|}{$\begin{array}{l}\text { Oxigênio } \\
\text { (ml/l) }\end{array}$} & \multicolumn{2}{|c|}{$\begin{array}{c}\text { Amônia } \\
(\mu \mathrm{M} / \mathrm{l})\end{array}$} \\
\hline & $0 \mathrm{~h}$ & $96 \mathrm{~h}$ & $\mathbf{O} \mathbf{h}$ & $96 \mathrm{~h}$ & $\mathbf{0 h}$ & $96 \mathrm{~h}$ \\
\hline Controle & 8,17 & 8,02 & 4,64 & 4,97 & 0,13 & 60,26 \\
\hline 1,0 & 8,17 & 7,69 & 4,12 & 5,21 & 39,94 & 70,39 \\
\hline 2,0 & 8,07 & 7,68 & 3,91 & 4,76 & 46,68 & 81,92 \\
\hline $\mathbf{5 , 0}$ & 8,05 & 7,72 & 4,36 & 3,58 & 90,18 & 123,52 \\
\hline 10,0 & 7,83 & 7,60 & 4,17 & 4,03 & 103,65 & 101,92 \\
\hline 20,0 & 7,50 & 7,53 & 4,29 & 4,11 & 150,21 & 120,72 \\
\hline 30,0 & 7,45 & 7,51 & 4,25 & 4,17 & 171,82 & 107,49 \\
\hline 50,0 & 7,06 & 7,49 & 4,17 & 3,99 & 174,21 & 99,87 \\
\hline
\end{tabular}

Tabela 3. Dados de pH, concentrações de oxigênio e de amônia, no início (0h) e no final ( $96 \mathrm{~h}$ ) do experimento, nas várias concentraçőes utilizadas da amostra $\mathrm{B}$

\begin{tabular}{ccccccc}
\hline $\begin{array}{c}\text { Concentração } \\
(\mathbf{\%})\end{array}$ & \multicolumn{2}{c}{$\mathbf{p H}$} & \multicolumn{2}{c}{$\begin{array}{c}\text { Oxigênio } \\
(\mathbf{m l} / \mathbf{l})\end{array}$} & \multicolumn{2}{c}{$\begin{array}{c}\text { Amônia } \\
(\boldsymbol{\mu M} \mathbf{M} / \mathbf{l})\end{array}$} \\
& $\mathbf{0 ~ h}$ & $\mathbf{9 6} \mathbf{~ h}$ & $\mathbf{0 ~ h}$ & $\mathbf{9 6 ~ h}$ & $\mathbf{0} \mathbf{~ h}$ & $\mathbf{9 6 ~ h}$ \\
\hline Controle & $\mathbf{8 , 1 5}$ & $\mathbf{8 , 0 0}$ & 5,30 & 4,74 & 0,13 & $\mathbf{1 5 , 0 1}$ \\
$\mathbf{0 , 0 0 5}$ & $\mathbf{8 , 1 4}$ & $\mathbf{8 , 1 0}$ & 5,43 & 5,56 & 0,13 & 16,16 \\
$\mathbf{0 , 0 1 0}$ & $\mathbf{8 , 1 5}$ & $\mathbf{8 , 0 6}$ & 5,49 & 5,90 & 0,13 & 7,12 \\
$\mathbf{0 , 0 5 0}$ & $\mathbf{8 , 1 6}$ & $\mathbf{8 , 0 5}$ & 5,47 & 5,46 & 0,43 & 18,84 \\
$\mathbf{0 , 1 0 0}$ & $\mathbf{8 , 1 6}$ & $\mathbf{8 , 0 7}$ & 5,50 & 5,92 & 0,73 & 38,83 \\
$\mathbf{0 , 1 5 0}$ & $\mathbf{8 , 1 5}$ & $\mathbf{8 , 0 4}$ & 5,36 & 5,87 & 0,93 & 30,54 \\
$\mathbf{0 , 2 5 0}$ & $\mathbf{8 , 1 6}$ & $\mathbf{8 , 0 2}$ & 5,43 & 5,89 & 1,14 & 37,39 \\
$\mathbf{0 , 3 5 0}$ & $\mathbf{8 , 1 5}$ & $\mathbf{8 , 0 4}$ & 5,49 & 5,74 & 1,23 & 19,57 \\
$\mathbf{0 , 5 0 0}$ & $\mathbf{8 , 1 5}$ & $\mathbf{8 , 0 7}$ & 5,71 & 5,92 & 1,26 & 35,49 \\
$\mathbf{0 , 8 0 0}$ & $\mathbf{8 , 1 6}$ & $\mathbf{8 , 1 0}$ & 5,80 & 5,91 & 1,30 & 20,41 \\
\hline
\end{tabular}



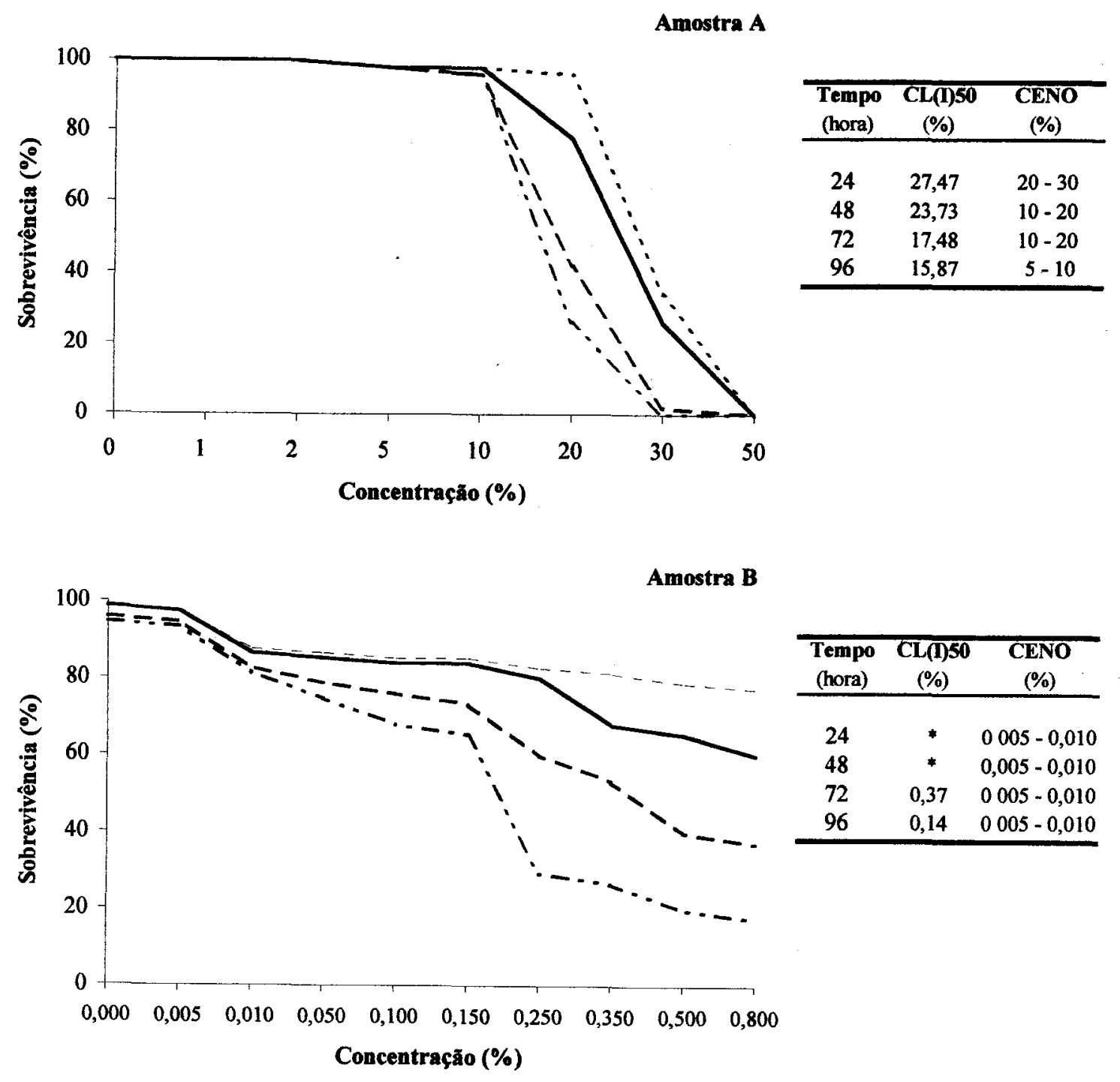

\begin{tabular}{|l|}
\hline-- Tempo de exposição 24 horas - Tempo de exposição 48 horas \\
--- Tempo de exposição 72 horas $-\cdots-$ Tempo de exposiçăo 96 horas
\end{tabular}

Fig. 1. Porcentagem de sobrevivência de $C$. sertulariarum nas várias concentrações das amostras $\mathrm{A}$ e $\mathrm{B}$, e valores de CENO e CL(I)so, para testes de 24, 48, 72 e 96 horas. 
Estimou-se, para cada amostra, a Concentração de Efeito Não Observado (CENO*) através do teste de Dunnet (Zar, 1984), e a Concentração Letal Inicial Média (CL(I)50*) utilizando-se o método de Hamilton et al. (1978). Os valores encontram-se na Figura 1.

Efeitos subletais também foram observados durante o experimento. A partir da concentração de $5 \%$ da amostra A e de $0,005 \%$ da amostra B, foram observadas alterações no comportamento dos gastrópodes, isto é, os animais ficaram inicialmente imóveis e posteriormente voltaram a se locomover vagarosamente. Em concentrações maiores $(20 \%$ da amostra A e $0,15 \%$ da amostra B), os animais encolheram-se e recolheram as antenas. Nas concentrações de 30 e $50 \%$ da amostra $\mathrm{A}$ e acima de $0,35 \%$ da amostra $\mathrm{B}$, os animais ao entrarem em contato com as soluções teste, secretaram um muco viscoso e formaram um bisso de fixação.

Os resultados obtidos mostram alguns aspectos importantes da toxicidade dos efluentes simulados e fornecem subsídios para a avaliação do método de tratamento a ser utilizado pela PETROBRÁS. Indicam também, a necessidade de acompanhamento das variações em sua composição química $\mathrm{e}$ de monitoramento permanente de possiveis efeitos ecotoxicológicos decorrentes de seu lançamento no Canal de São Sebastião.

Tanto a amostra A como a B, ambas de composição complexa, sem dúvida sofreram alteraçôes na sua composição e no seu potencial tóxico durante a estocagem. Examinando-se os resultados da análise química das amostras verificou-se que, no caso da amostra $\mathrm{A}$, a DBO e a DQO aumentaram com a estocagem, refletindo possíveis alterações químicas (Phan et al., 1994).

Os experimentos com a amostra A revelaram que, decorridas 24 horas de exposição, a concentração máxima onde não é observado efeito estatisticamente significativo na mortalidade de $C$. sertulariarum, está entre 20 e $30 \%$ da concentração da solução. A partir dessas concentrações e após 24 horas, a mortalidade desses animais já é estatisticamente diferente daquela do grupo controle. Por outro lado, quando o período de exposição é aumentado, para além das 24 horas, o valor da CENO tende a diminuir. $\mathrm{O}$ aumento da taxa de mortalidade e portanto, a diminuição dos valores da CENO e da CL(I) 50 são relativamente comuns nos testes de toxicidade. Isto devido,

\footnotetext{
(*) CENO - Maior concentração teste que não causa efeito significativamente diferente do controle.

$\left.{ }^{(* *}\right) \mathrm{CL}(\mathrm{I})_{50}$ - concentração teste letal a $50 \%$ dos organismos.
}

provavelmente, ao aumento da ação da substância tóxica sobre os organismos teste em exposiç̃̃es prolongadas (Reish et al., 1989).

Os testes realizados com a amostra B indicaram que esta apresenta um potencial tóxico bastante diferente do apresentado pela amostra A. Após o experimento preliminar, observou-se que a concentração máxima, onde nenhum efeito sobre a sobrevivência dos animais era observado, estava abaixo de $0,010 \%$. No experimento seguinte, observouse que a CENO, após 24 horas estava entre 0,005 e $0,010 \%$, correspondendo ao obtido no experimento preliminar.

Os valores da CENO e da CL(I)50 obtidos, tanto para a amostra A como para a amostra B, mostram a alta toxicidade das mesmas. Deve-se destacar ainda, que as alterações comportamentais e fisiológicas em animais expostos às substâncias tóxicas, podem ocorrer em concentrações até $75 \%$ menores do que a $\mathrm{CL}(\mathrm{I})_{50}$ (Diamont et al., 1990; Little \& Finger, 1990).

Com relação ao comportamento dos animais em presença das amostras A e B do efluente, foi observada uma intensa secreção de muco e formação de bisso em um grande número de animais em tempo reduzido, naqueles submetidos a soluções teste da amostra B. O muco produzido e a diminuição do metabolismo, devido à fixação dos animais, devem servir, provavelmente, como proteção. Estudos mais detalhados sobre a toxicidade do efluente, bem como do comportamento e fisiologia de moluscos desta e de outras espécies, tornam-se necessários a fim de poder compreender melhor os efeitos dos efluentes a serem lançados pela PETROBRÁS.

Os resultados da CL(I)50 obtidos neste trabalho, são importante contribuição à determinação do tratamento que deverá sofrer o efluente, que será lançado através de emissário submarino no terminal do Canal de São Sebastião. O tratamento deverá também contemplar duas outras questões: o fato do efluente apresentar alta salinidade e de estar sendo lançado num sistema já estressado por inúmeros derrames de petróleo. A presença de substâncias tóxicas aliadas a esses dois fatores podem induzir efeitos cumulativos, com prejuízos à biota local.

Testes de toxicidade visando auxiliar no estabelecimento de tratamento de efluentes como o caso do Terminal Marítimo "Almirante Barroso" (TEBAR), parece-nos ser um procedimento que deveria ser praticado em todos os lançamentos submarinos de efluentes industriais e mesmo de esgotos municipais, afim de se evitar impactos ecotoxicológicos indesejáveis sobre o ecossistema marinho. 


\section{Referências bibliográficas}

APHA. American Public Health Association. 1985. Standard methods for the examination of water and wastewater. $16^{\text {th }}$ ed. Washington, APHA, $1268 \mathrm{p}$.

Diamont, J. M.; Marolyn, J. P. \& Gruber, D. 1990. Rapid detection of sublethal toxicity using fish ventilatory behavior. Environ. Toxicol. Chem., 9:3-11.

Hamilton, M. A.; Russo, R. C. \& Thurston, R. V. 1978. Trimmed Spearman-Karber method for estimating median lethal concentrations in toxicity bioassays. Environ. Sci. Technol., 12(4):417-422.

Little, E. W. \& Finger, S. E. 1990. Swimming behavior as an indicator of sublethal toxicity in fish. Environ. Toxicol. Chem., 9:13-19.
Phan, V. N.; Gomes, V. \& Passos, M. J. A. C. R. 1994. Avaliação prévia da toxicidade de um efluente simulado derivado de petróleo sobre Promysis atlantica (Crustacea, Mysidacea). Bolm Inst. oceanogr., S Paulo, 42(1/2):129-141.

Reish, D. J.; Asato, S. L. \& Lemay, J. A. 1989. The effect of cadmium and DDT on the survival and regeneration in the amphinomid polychaete Eurythae complanata. In: Proceedings of the 7 symposium of marine biology. La Paz, BCS. 10\% p.107-111.

Zar, J. H. 1984. Biostatistical analysis. Englewood Cliffs, Prentice-Hall. 718p.

(Manuscrito recebido 05 junho 1996; revisado 24 abril 1997; aceito 08 dezembro 1997) 